GRASAS Y ACEITES 67 (3)

July-September 2016, e152

ISSN-L: 0017-3495

doi: http://dx.doi.org/10.3989/gya.0440161

\title{
Influence of the type of cellulosic derivatives on the texture, and oxidative and thermal stability of soybean oil oleogel
}

\author{
A. Totosaus ${ }^{\bowtie}$, R. Gonzaléz-Gonzaléz and M. Fragoso \\ Food Science Lab \& Pilot Plant. Tecnológico Estudios Superiores Ecatepec. Av. Tecnológico esq. Av. \\ Central s/n., Ecatepec 55210, México \\ ${ }^{\square}$ Corresponding author: alfonso.totosaus@gmail.com
}

Submitted: 05 April 2016; Accepted: 27 May 2016

SUMMARY: The use oleogels (defined as edible oils entrapped in a three-dimensional network employing a self-assembled structuring agent) has recently been proposed to replace saturated fat or trans-fats in foods. In this work the effects of different cellulose derivative mixtures (Avicel, ethyl cellulose and $\alpha$-cellulose) on lipid stability, glass transition temperature and the texture of soybean oil oleogels were determined by employing a mixture design approach. Avicel affected lipid stability, increasing the oxidative rancidity and peroxide values of oleogels. Oleogels with higher proportions of Avicel also presented higher transition temperatures. A higher percent of ethyl cellulose and $\alpha$-cellulose in the oleogel mixture resulted in a more stable system with lower oil rancidity and lower glass transition temperatures. In addition, Avicel resulted in a softer and less tacky texture, an important characteristic to consider for food applications.

KEYWORDS: Cellulose derivatives; DSC; FTIR; Lipid oxidation; Oleogel; Soybean oil

RESUMEN: Influencia del tipo de derivado celulósico sobre la textura y la estabilidad oxidativa y térmica de oleogeles de aceite de soja. Recientemente, ha sido propuesto el uso de oleogeles (definido como aceites comestibles atrapados en una red tridimensional que ocupa un agente estructurante de auto-ensamblado) como substituto de grasa saturada o grasas trans en alimentos. En este trabajo el efecto de mezclas de diferentes derivados celulósicos (Avicel, etil celulosa y $\alpha$-celulosa) sobre la estabilidad de lípidos, temperaturas de transición térmica y textura de oleogeles de aceite de soja fueron determinados utilizando un diseño de mezclas. Avicel afectó la estabilidad de lípidos, aumentando la rancidez oxidativa y valores de peróxido en los oleogeles. Oleogeles con mayores proporciones de Avicel también presentaron temperaturas de transición térmica más altas. Porcentajes más altos de etil celulosa y $\alpha$-celulosa resultaron en un sistema más estable con menor rancidez oxidativa y menores temperaturas de transición térmica. Sin embargo, Avicel resultó en una textura más suave y menos pegajosa, una característica importante a considerar para su aplicación en alimentos.

PALABRAS CLAVE: Aceite de soja; Derivados celulósicos; DSC; FTIR; Oleogel; Oxidación de lípidos

Citation/Cómo citar este artículo: Totosaus A, Gonzaléz-Gonzaléz R, Fragoso M. 2016. Influence of the type of cellulosic derivatives on the texture, and oxidative and thermal stability of soybean oil oleogel. Grasas Aceites, 67 (3): e152. doi: http://dx.doi.org/10.3989/gya.0440161.

Copyright: (C) 2016 CSIC. This is an open-access article distributed under the terms of the Creative Commons Attribution-Non Commercial (by-nc) Spain 3.0 Licence. 


\section{INTRODUCTION}

An oleogel can be defined as an organic liquid entrapped withina thermo-reversible, three-dimensional gel network. This type of thermo-reversible gelation is also called Cold Induced Gelation, and gel types arise upon the formation of non-covalent junction zones, thus termed 'physical' gels (Dassanayake et al., 2011; Davidovich-Pinhas et al., 2015). Oleogels maintain the fatty acid profile of the gelled oils, such as the functionality and texture of the final products (Stortz et al., 2012). Several food grade compounds as structuring agents with oilgelling properties had been proposed as gelators, like sugar alcohol-based mannitol dioctanoate and sorbitol dioctanoate (Jadhav et al., 2013), natural waxes (Doan et al., 2015), shellac resin (Patel et al., 2014), and chitin, the second most abundant organic material in nature after cellulose (Nikifordis and Scholten, 2015). Cellulose is the major building block of the cell-wall structures of higher plants, and despite the large variety of cellulose derivatives that have been made, only a few cellulose ethers find application and are approved for use in foodstuffs, where the most widely used cellulose derivative is sodium carboxymethylcellulose (Coffey et al., 2006). Cellulose derivatives, such as hydroxyl propyl cellulose, hydroxyl propyl methyl cellulose, hydroxyethyl cellulose, have been used to produce oleogels (Pernetti et al., 2007). The use of oleogel as a saturated fat replacer in foods had implications on food texture. In frankfurters, replacing saturated fats with ethyl cellulose oleogel to maintain the fatty acid profile of canola oil resulted in the same hardness as control samples, where oleogel appears to resist chopping in a similar manner to beef fat, with larger fat globule size (Zetzl et al., 2012).

However, an important factor in oleogel elaboration is the temperature necessary for the complete dissolution of the cellulose derivative polymers in the vegetable oil, since this can be approximately $125-150{ }^{\circ} \mathrm{C}$, depending on the glass transition temperature of specific cellulose derivative and polymer molecular weight (Co and Marangoni, 2012). At these temperatures, changes like oxidation of the oil component could lead to deterioration of the oleogel quality (Gravelle et al., 2012). Since cellulose derivatives with different structures had different glass transition temperatures, mixtures of these compounds would affect the transition temperatures of oleogel, together with their textural characteristics.

The objective of this work was to determinate the effect of different cellulose derivatives (microcrystalline cellulose/sodium carboxymethylcellulose, ethyl cellulose and $\alpha$-cellulose) on lipid and thermal stability and texture of soybean oil oleogels, as a promising fat replacer in thermally processed foods.

\section{MATERIALS AND METHODS}

\subsection{Oleogel elaboration}

The elaboration Oleogel has been adapted to the experimental conditions described by Gravelle et al. (2013). The celluloses employed were Avicel ${ }^{\circledR}$ RC-591, a mixture of micro-crystalline cellulose and sodium carboxymethylcellulose (CMC) (FMC Biopolymers, Philadelphia, USA), ethyl cellulose (viscosity $100 \mathrm{cP}$, Sigma-Aldrich, St. Louis, USA) and $\alpha$-cellulose (Sigma-Aldrich, St Louis, USA). Different cellulose derivative mixtures were weighed $(11 \%, \mathrm{w} / \mathrm{w})$ and mixed with $3.67 \%(\mathrm{w} / \mathrm{w})$ of Panodan 165 (mono- and diacetyl tartaric acid esters, E472e, Danisco, Copenhagen, Denmark) as surfactant, and $85.33 \%(\mathrm{w} / \mathrm{w})$ Nutrioli ${ }^{\circledR}$ soybean oil (Grupo Ragasa, Monterrey, Mexico). The solution was then heated at $140{ }^{\circ} \mathrm{C}$ employing a magnetic stirring heating plate at a constant rate for approximately 20-30 min, until total cellulose solubilization. After completion of the heating process, each molten oleogel batch was poured in $100 \mathrm{~mL}$ bakers covered with petrifilm ${ }^{\circledR}$ and cooled down at room temperature before being stored (at least $24 \mathrm{~h}$ ) under refrigeration.

\subsection{Oxidative stability}

The lipid stability of the edible oil employed was determined by measuring the oxidative rancidity and peroxide value.

Oxidative rancidity was determined as the amount of malondialdehyde, as the secondary lipid oxidation product, after employing the thiobarbituric acid method described by Yun and Surh (2012). In a $25 \mathrm{~mL}$ volumetric flask, a $0.1 \mathrm{~g}$ of sample was weighed and $0.1 \mathrm{~g}$ of BHT was added to prevent further oxidation. The sample was then dissolved in $5 \mathrm{~mL}$ of 1-butanol and $5 \mathrm{~mL}$ of a 2-thiobarbituric acid solution $(0.014 \mathrm{M})$ in 1-butanol. The samples were incubated in boiling water for $2 \mathrm{~h}$ and then cooled with tap water to stop the reaction. After 10 minutes absorbance was measured at $523 \mathrm{~nm}$. Malondialdehyde ( $\mathrm{mg} / \mathrm{kg}$ of sample) concentration was determined according to a 1,1,3,3-tetraethoxypropane $(0.0004 \mathrm{M})$ standard curve.

Peroxide value was determined according to the AOAC Official Method 965.33 (AOAC, 1999). Five $\mathrm{g}$ of sample were dissolved in $30 \mathrm{~mL}$ of a $\mathrm{CH}_{3} \mathrm{COOH}-\mathrm{CHCl}_{3}$ solution $(3: 2 \mathrm{v} / \mathrm{v}) .0 .5 \mathrm{~mL}$ of a saturated freshly prepared KI solution was added and after shaking for one minute, $30 \mathrm{~mL}$ of distilled water were added. The sample was titrated with 0.1 $\mathrm{N} \mathrm{Na}_{2} \mathrm{~S}_{2} \mathrm{O}_{3}$ until the yellow color almost gone. 0.5 $\mathrm{mL}$ of a $1 \%$ freshly prepared starch solution was added to continue titration by shaking vigorously until the blue color had disappeared. Peroxide value was calculated according to: 


$$
\mathrm{PV}(\mathrm{meq} / \mathrm{kg} \text { sample })=\frac{\mathrm{S} \times \mathrm{N} \times 1000}{\mathrm{~g} \text { sample }}
$$

Where

$\mathrm{S}=\mathrm{mL} \mathrm{Na} \mathrm{S}_{2} \mathrm{O}_{3}$ (blank corrected)

$\mathrm{N}=$ Normality $\mathrm{Na}_{2} \mathrm{~S}_{2} \mathrm{O}_{3}$ solution

\subsection{Thermal stability by differential scanning calorimetry}

The thermal properties of oleogels were determined using a Mettler DSC1 differential scanning calorimeter (Mettler Toledo, Columbus, USA). Oleogel samples $(0.005 \pm 0.001 \mathrm{~g})$ were weighed in an aluminum pan and sealed. Samples were heated from 30 to $80{ }^{\circ} \mathrm{C}$ at $10{ }^{\circ} \mathrm{C} / \mathrm{min}$ to eliminate moisture, and then until $300{ }^{\circ} \mathrm{C}$ at $10^{\circ} \mathrm{C} / \mathrm{min}$ with air flow purge. The transition temperature peak and enthalpy were calculated from the thermograms.

\subsection{Texture}

Oleogel texture was determined according to the back extrusion methodology described by Gravelle et al. (2014). Oleogels in $100 \mathrm{~mL}$ beakers were penetrated $15 \mathrm{~mm}$ from the surface at $1.0 \mathrm{~mm} / \mathrm{s}$ with a $40 \mathrm{~mm}$ diameter flat acrylic probe in a LFRA 4500 texturometer (Brookfield Engineering, Middleborough, England), at room temperature. From force-time curves maximum force (peak force during back extrusion) and tackiness (adhesive force peak during probe return after reaching the programmed depth) were calculated. The results are the average of at least three different oleogel batches.

\subsection{Fourier transform infra-red spectroscopy}

For the infra-red analysis, oleo gel films were prepared by placing the sample between two glass microscope slides compressed until obtaining a thin film. Single-beam spectra of the samples were collected against a background of air and presented in transmittance units in an infra-red spectrophotomer Buck M530 (Buck Scientific, East Norwalk), scanning from 4000 to $1000 \mathrm{~cm}^{-1}$, at a nominal resolution of $10 \mathrm{~cm}^{-1}$.

\subsection{Experimental design and data analysis}

A three-component constrained simplex lattice mixture design was used. The mixture components consisted of Avicel microcrystalline cellulose/CMC $\left(\mathrm{X}_{1}, \mathrm{~A}-\mathrm{C}\right)$, ethyl cellulose $\left(\mathrm{X}_{2}, \mathrm{E}-\mathrm{C}\right)$, and $\alpha$-cellulose $\left(\mathrm{X}_{3}, \alpha-\mathrm{C}\right)$. Components were expressed as fractions of the mixture and the sum $\left(\mathrm{X}_{1}+\mathrm{X}_{2}+\mathrm{X}_{3}\right)$ of the proportions was one. The ten points consisted of three single- ingredient systems, three two-ingredient mixtures and four three-ingredient mixtures (Figure 1).

Scheffe's canonical special cubic equation for 3 components was fitted to the data collected at each experimental point using backward stepwise multiple regression analysis as described by Cornell (1980). This canonical model differs from full polynomial models in that it does not contain a constant term, i.e., it has a zero intercept. Variables in the regression models, which represent two-ingredient or three-ingredient interaction terms, were referred to as "non-linear" terms. The canonical special cubic equation postulated was:

$$
\begin{aligned}
\eta= & \beta_{1} X_{1}+\beta_{2} X_{2}+\beta_{3} X_{3}+\beta_{12} X_{12}+ \\
& \beta_{13} X_{13}+\beta_{23} X_{23}+\beta_{123} X_{123}
\end{aligned}
$$
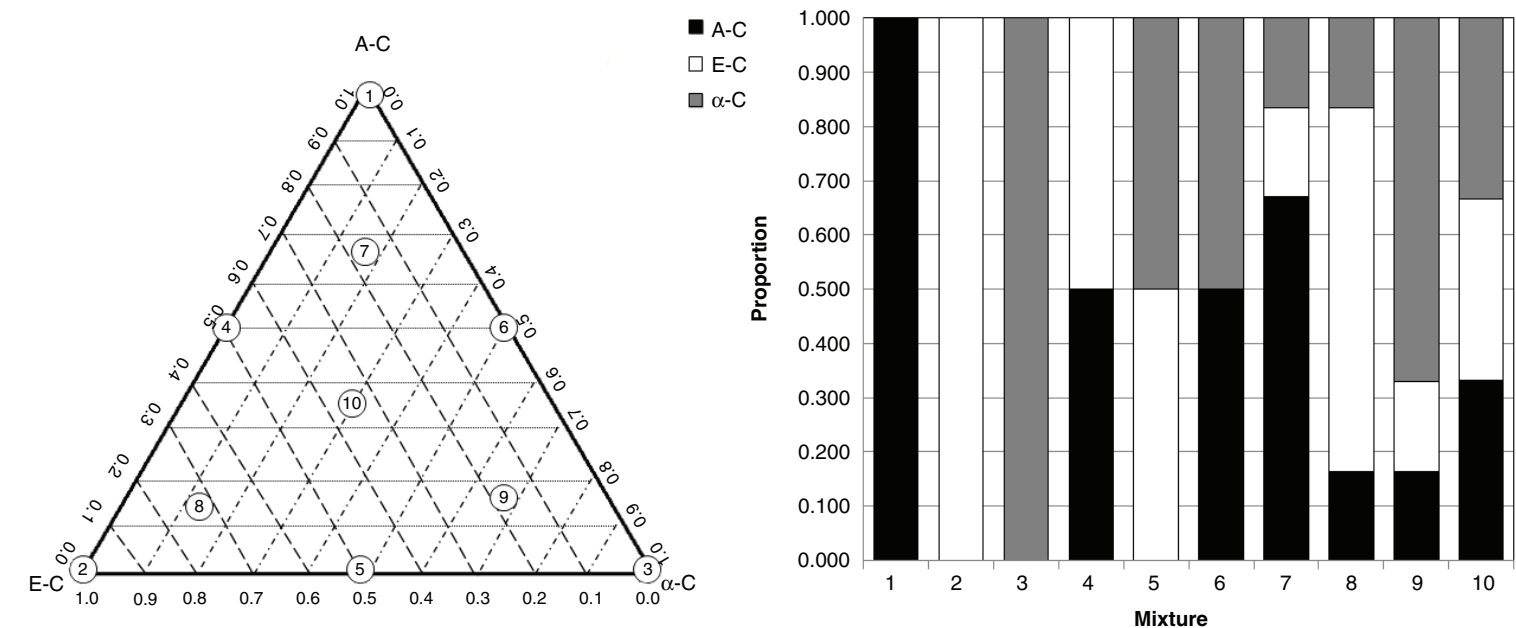

Figure 1. Constrained region in the ten-point simplex centroid design for the three ingredients mixtures (A-C: Avicel microcrystalline cellulose/CMC, E-C: ethyl cellulose, $\alpha$-C: $\alpha$-cellulose). 
where $\eta$ is a predictive dependent variable (lipid stability, thermal stability and texture); $\beta_{1}, \beta_{2}, \beta_{3}$, $\beta_{12}, \beta_{13}, \beta_{23}$ and $\beta_{123}$ are the corresponding parameter estimates for each linear and cross-product term produced for the prediction models for Avicel (A-C, $\left.\mathrm{X}_{1}\right)$, ethyl-cellulose $\left(\mathrm{E}-\mathrm{C}, \mathrm{X}_{2}\right)$, and $\alpha$-cellulose $(\alpha-\mathrm{C}$, $\mathrm{X}_{3}$ ). The data were analyzed to obtain regression coefficients and iso-response curves with SAS statistical analysis software version 8.0, on the ADX interface (SAS Institute, Cary, USA).

\section{RESULTS}

\subsection{Oxidative stability}

Lipid stability was affected by the cellulose mixtures. Mixtures with a higher Avicel percent resulted in elevated oxidative rancidity values (mixtures 1 and 7, followed by mixtures 4 and 6). The lowest lipid degradation was observed in mixtures containing ethyl cellulose (mixture 2, followed by mixtures 8 and 5). As for lipid rancidity, a higher proportion of Avicel resulted in higher lipid peroxide values, and binary mixtures of Avicel with both ethyl cellulose and $\alpha$-cellulose presented the same value for this parameter (mixtures 4 and 6). The lowest peroxide value was obtained with the binary mixture ethyl cellulose/ $\alpha$-cellulose (mixture 5, 0.500). In a ternary mixture to improve lipid stability, the lower the CMC proportions, the lower the peroxide values (Table 1).

In the regression analysis for the peroxide value Avicel presented a highly significant $(\mathrm{p}<0.01)$ effect, whereas both ethyl cellulose and $\alpha$-cellulose presented a significant $(\mathrm{p}<0.05)$ effect, with lower estimated parameter values as well (Table 2). In the regression analysis for oxidative rancidity, only linear terms presented a highly significant $(p<0.01)$ effect on this parameter, with a higher estimated parameter value for Avicel. In iso-response curves (Figure 2a) higher oxidative rancidity values can be observed in the Avicel vertex (0.120). The lowest rancidity was observed in the ethyl cellulose vertex $(0.060)$, followed by the $\alpha$-cellulose vertex $(0.090)$. When ethyl cellulose was incorporated to the Avicel mixtures, the oxidative rancidity values decreased in higher proportions than for $\alpha$-cellulose mixtures (binary mixtures 5 and 6). Lower rancidity values were detected in ethyl cellulose and $\alpha$-cellulose binary mixtures. In the ternary mixtures, the higher the ethyl cellulose percentage, the lower the observed rancidity. For the peroxide value iso-response curves (Figure 2b), higher values for this parameter were observed at the Avicel vertex (mixture 1, 1.750), with the same value in both the ethyl cellulose and $\alpha$-cellulose vertices (mixtures 2 and 3, 0.750).

\subsection{Thermal stability by differential scanning calorimetry}

In oleogels with higher proportions of Avicel (formulations 1 and 7) the transition temperature was higher. The lowest transition temperature observed was in oleogels with ethyl cellulose (formulations 2 and 8), followed by those containing higher proportions of $\alpha$-cellulose (formulations 3 and 9). Melting enthalpy presented the same tendency (Table 1). The melting temperature peak was affected by the three cellulose linear terms in a highly significant $(p<0.01)$ way, with a higher estimate parameter value for Avicel, followed by $\alpha$-cellulose and ethyl cellulose. For the melting enthalpy, only Avicel presented a significant $(p<0.05)$ effect on the energy detected during thermal analysis (Table 2). The higher melting temperature was also higher in the Avicel vertex, but decreasing with ethyl cellulose and/or $\alpha$-cellulose

TABLE 1. Experimental results for the different oleogel mixtures

\begin{tabular}{|c|c|c|c|c|c|c|c|c|}
\hline \multirow[b]{3}{*}{ Mixture } & \multicolumn{2}{|c|}{ Lipid stability } & \multirow{2}{*}{\multicolumn{3}{|c|}{$\begin{array}{c}\text { Thermal stability } \\
\text { Transition temperature }\left({ }^{\circ} \mathrm{C}\right)\end{array}$}} & \multicolumn{3}{|c|}{ Texture } \\
\hline & \multirow{2}{*}{$\begin{array}{l}\text { Oxidative rancidity } \\
\text { (mg MDH/kg } \\
\text { sample) }\end{array}$} & \multirow{2}{*}{$\begin{array}{c}\text { Peroxide } \\
\text { value (meq/kg } \\
\text { sample) }\end{array}$} & & & & \multirow{2}{*}{$\begin{array}{l}\text { Melting } \\
\text { Enthalpy } \\
(\mathrm{J} / \mathrm{g})\end{array}$} & \multirow{2}{*}{$\underset{\text { force }(N)}{\operatorname{Maximum}}$} & \multirow[b]{2}{*}{ Tackiness (N) } \\
\hline & & & Onset & Midpoint & Offset & & & \\
\hline 1 & 1.7514 & 0.1345 & 86.60 & 120.42 & 166.00 & 103.00 & 0.99 & -0.39 \\
\hline 2 & 0.1926 & 0.0429 & 42.30 & 54.37 & 69.70 & 16.00 & 8.39 & -3.18 \\
\hline 3 & 0.6576 & 0.0796 & 64.46 & 91.48 & 122.00 & 37.10 & 6.42 & -1.92 \\
\hline 4 & 1.1027 & 0.0869 & 65.20 & 85.60 & 120.60 & 53.20 & 4.28 & -1.89 \\
\hline 5 & 0.6108 & 0.0621 & 66.56 & 85.52 & 125.57 & 21.60 & 10.35 & -4.86 \\
\hline 6 & 0.9688 & 0.1117 & 61.43 & 78.37 & 122.60 & 100.70 & 3.19 & -1.78 \\
\hline 7 & 1.7231 & 0.1288 & 79.44 & 95.71 & 138.46 & 132.10 & 3.87 & -1.11 \\
\hline 8 & 0.5694 & 0.1053 & 45.54 & 71.70 & 102.60 & 72.11 & 4.03 & -3.72 \\
\hline 9 & 0.6997 & 0.1179 & 49.20 & 84.20 & 126.30 & 109.44 & 3.92 & -1.65 \\
\hline 10 & 0.9278 & 0.0989 & 67.40 & 84.77 & 123.20 & 74.60 & 3.53 & -2.07 \\
\hline
\end{tabular}


Influence of the type of cellulosic derivatives on the texture, and oxidative and thermal stability of soybean oil oleogel $\bullet 5$

TABLE 2. Regression coefficients and correlation for the adjusted models to experimental data in mixture design

\begin{tabular}{|c|c|c|c|c|c|c|c|c|}
\hline \multirow[b]{2}{*}{ Variable } & \multicolumn{3}{|c|}{ Linear } & \multicolumn{3}{|c|}{ Quadratic } & \multirow[b]{2}{*}{$\beta_{123}$} & \multirow[b]{2}{*}{$\mathbf{R}^{2}$} \\
\hline & $\beta_{1}$ & $\boldsymbol{\beta}_{2}$ & $\boldsymbol{\beta}_{3}$ & $\beta_{12}$ & $\beta_{13}$ & $\beta_{23}$ & & \\
\hline Oxidative rancidity (mg MDH/kg) & $1.78 * *$ & $0.44 *$ & $0.53^{*}$ & 0.57 & -1.04 & -0.23 & 0.009 & 0.8460 \\
\hline Peroxide value (meq /kg) & $0.14 * *$ & $0.05 * *$ & $0.09 * *$ & 0.04 & 0.06 & 0.06 & 0.49 & 0.8180 \\
\hline Maximum force $(\mathrm{N})$ & 2.70 & $5.95^{*}$ & $3.17^{*}$ & -1.82 & 0.86 & 17.62 & 5.54 & 0.7414 \\
\hline Tackiness (N) & 0.89 & $-3.70 * *$ & $-2.47^{*}$ & 0.37 & -0.96 & -6.81 & -1.00 & 0.7617 \\
\hline Transition temp. onset $\left({ }^{\circ} \mathrm{C}\right)$ & $83.40^{* *}$ & $47.75^{*}$ & $60.29 *$ & 33.28 & -46.51 & -3.13 & 15.01 & 0.7649 \\
\hline Transition temp. midpoint $\left({ }^{\circ} \mathrm{C}\right)$ & $115.99 * *$ & $58.93^{* *}$ & $90.43^{* *}$ & 17.62 & -97.42 & 27.05 & -26.35 & 0.8531 \\
\hline Transition temp. offset $\left({ }^{\circ} \mathrm{C}\right)$ & $159.60 * *$ & $76.79 *$ & $121.18^{* *}$ & 42.14 & -71.23 & 69.95 & -13.27 & 0.8391 \\
\hline Enthalpy $(\mathrm{J} / \mathrm{g})$ & $103.74 *$ & 15.27 & 40.28 & 46.9 & 202.98 & 57.48 & 46.54 & 0.8559 \\
\hline
\end{tabular}

$\beta_{1}$ : Avicel (microcrystalline cellulose/CMC), $\beta_{2}$ : ethyl cellulose, $\beta_{3}: \alpha$-cellulose.

$*$ Significant $(\mathrm{p}<0.05)$

** Highly significant $(\mathrm{p}<0.01)$.
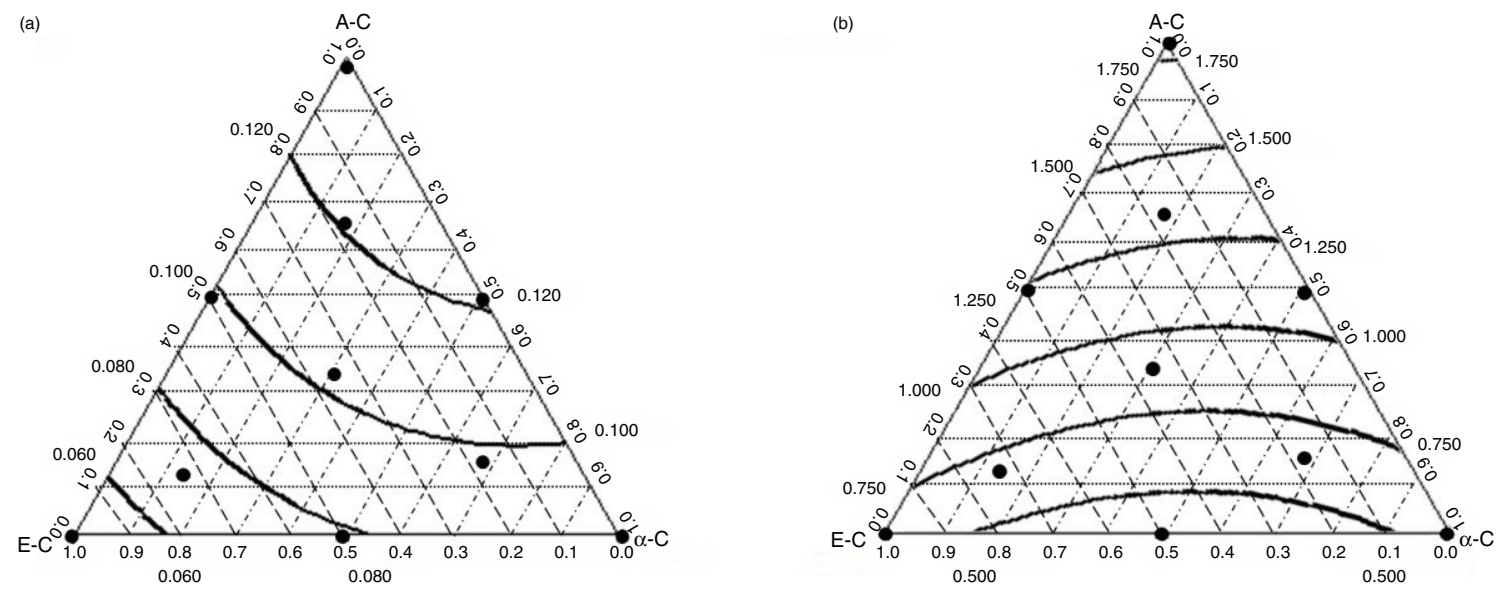

FIGURE 2. Iso-response contour plots of special cubic model for lipid stability for oleogels (a) oxidative rancidity and (b) peroxide value (A-C: Avicel microcrystalline cellulose/CMC, E-C: ethyl cellulose, $\alpha$-C: $\alpha$-cellulose).

(reflected in lower temperature values down through ethyl cellulose and/or $\alpha$-cellulose legs) (Figures 3a, $\mathrm{b}$, and $\mathrm{c}$ ). At the same time, since higher transition temperatures imply higher melting peaks (enthalpy change, $\Delta \mathrm{H}$ ), the melting enthalpy in the Avicel vertex was higher as compared to the one observed in the ethyl cellulose and/or $\alpha$-cellulose vertex. Combinations of ethyl cellulose/ $\alpha$-cellulose gave the lowest melting enthalpy values (Figure 3d).

\subsection{Texture}

Oleogel texture was affected by the different cellulose mixtures. A softer texture was obtained in mixtures containing only Avicel (mixtures 1). Oleogel mixtures containing ethyl cellulose obtained the hardest texture (mixtures 2 and $8)$, where the binary mixture ethyl cellulose/ $\alpha$ cellulose mixture resulted in the toughest texture (mixture 5) (Table 1). In regression analysis, both ethyl cellulose and $\alpha$-cellulose linear terms had a significant $(\mathrm{p}<0.05)$ effect on the oleogels' maximum force (Table 2). In the iso-response curve, lower force values were observed in the Avicel vertex, and the oleogel hardness increased when the Avicel concentration decreased and was compensated with ethyl cellulose and/or $\alpha$-cellulose. Tougher oleogels were obtained in the ethyl cellulose vertex. Combinations of ethyl cellulose/ $\alpha$-cellulose presented higher values for this parameter (Figure 4a).

The oleogel tackiness was lower when Avicel was employed in the oleogel formulation (mixtures 1 and 7). Better adhesiveness was observed in the binary mixture ethyl cellulose/ $\alpha$-cellulose (mixture 5), followed by the ethyl cellulose oleogel (mixture 2) (Table 1). Ethyl cellulose linear terms presented a highly significant $(\mathrm{p}<0.01)$ effect on tackiness, and $\alpha$-cellulose presented a significant $(p<0.05)$ effect on this parameter 

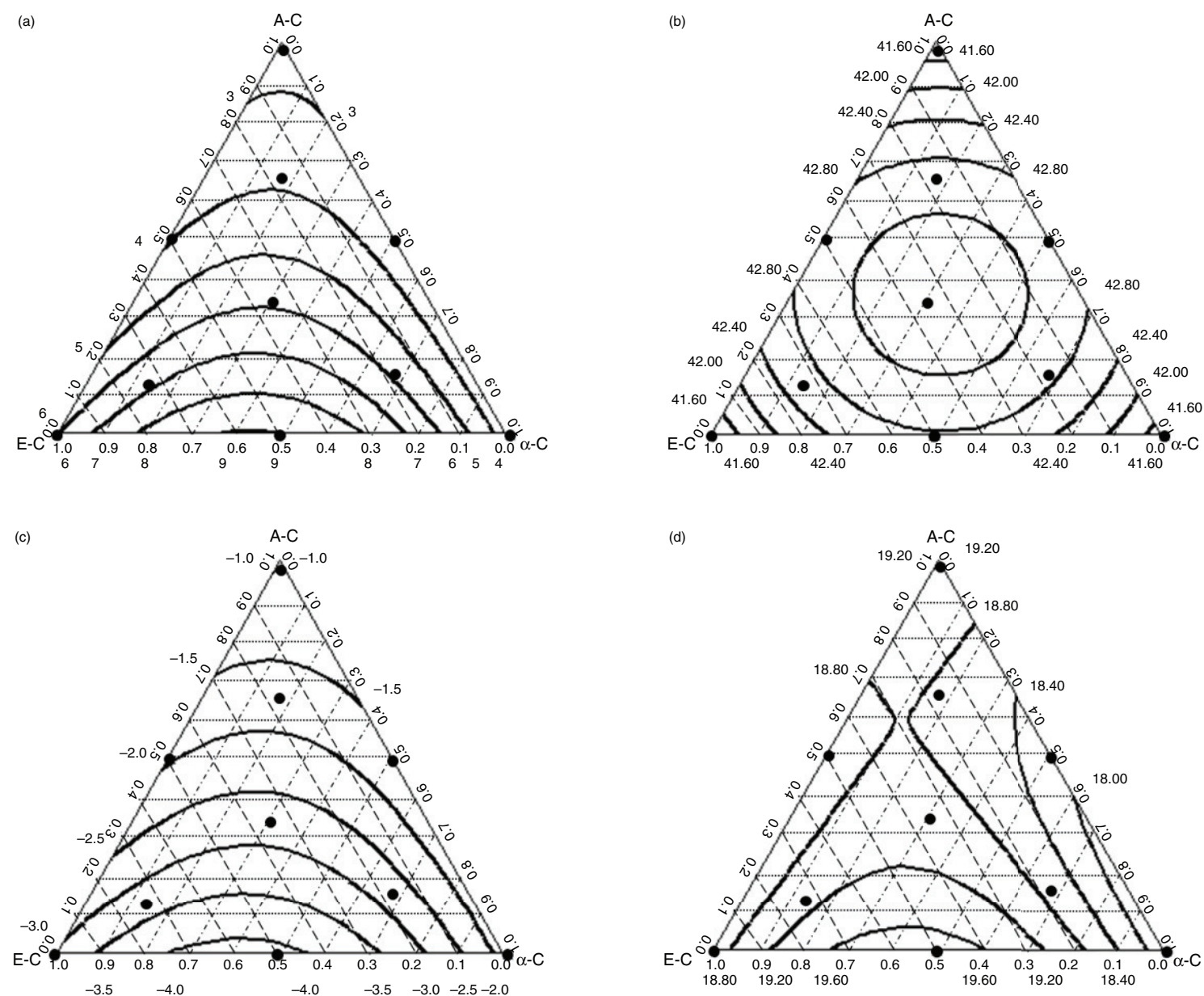

FIGURE 3. Iso-response contour plots of special cubic model for thermal properties for oleogels: transition temperature (a) onset, (b) midpoint, (c) offset, and (d) melting enthalpy (A-C: Avicel microcrystalline cellulose/CMC, E-C: ethyl cellulose, $\alpha$-C: $\alpha$-cellulose).

as well (Table 2). The relatively higher proportions of Avicel resulted in a less adhesive texture. Decreasing Avicel proportions in oleogels' formulation increased this parameter, where a higher ethyl cellulose proportion resulted in higher tackiness values (Figure 4b).

\subsection{Fourier transform infrared spectroscopy}

In the infrared spectra, the main structural differences related to different functional groups in cellulose derivatives employed in oleogels' elaboration can be appreciated. The main structural differences were observed in the $1000-1300 \mathrm{~cm}^{-1}$ ranges (mainly $\mathrm{C}-\mathrm{C}$ stretching and $\mathrm{COH}$ and $\mathrm{CCH}$ deformation vibrations), and above $3000 \mathrm{~cm}^{-1}$, depending on the cellulose type or their mixture (Figure 5).

\section{DISCUSSION}

\subsection{Oxidative stability}

These results indicate that the presence of Avicel affected the lipid stability during oleogel formation, resulting in higher rancidity and peroxide values. The effect associated to this phenomenon is the cellulose combination in Avicel (microcrystalline cellulose/CMC). Although microcrystalline cellulose is hydrophobic and contains $\mathrm{OH}$ groups, $\mathrm{CMC}$ is a hydrophilic polymer that presents a carboxyl group as a substituent. The Carboxyl group is an electron-withdrawing group with no radical scavenging activity (Thiago et al., 2008), resulting in a lower lipid stability. In the same manner, Gravelle et al. (2012) reported that a longer holding time at $140{ }^{\circ} \mathrm{C}$, or the surfactant type, affected the peroxide 
Influence of the type of cellulosic derivatives on the texture, and oxidative and thermal stability of soybean oil oleogel 7
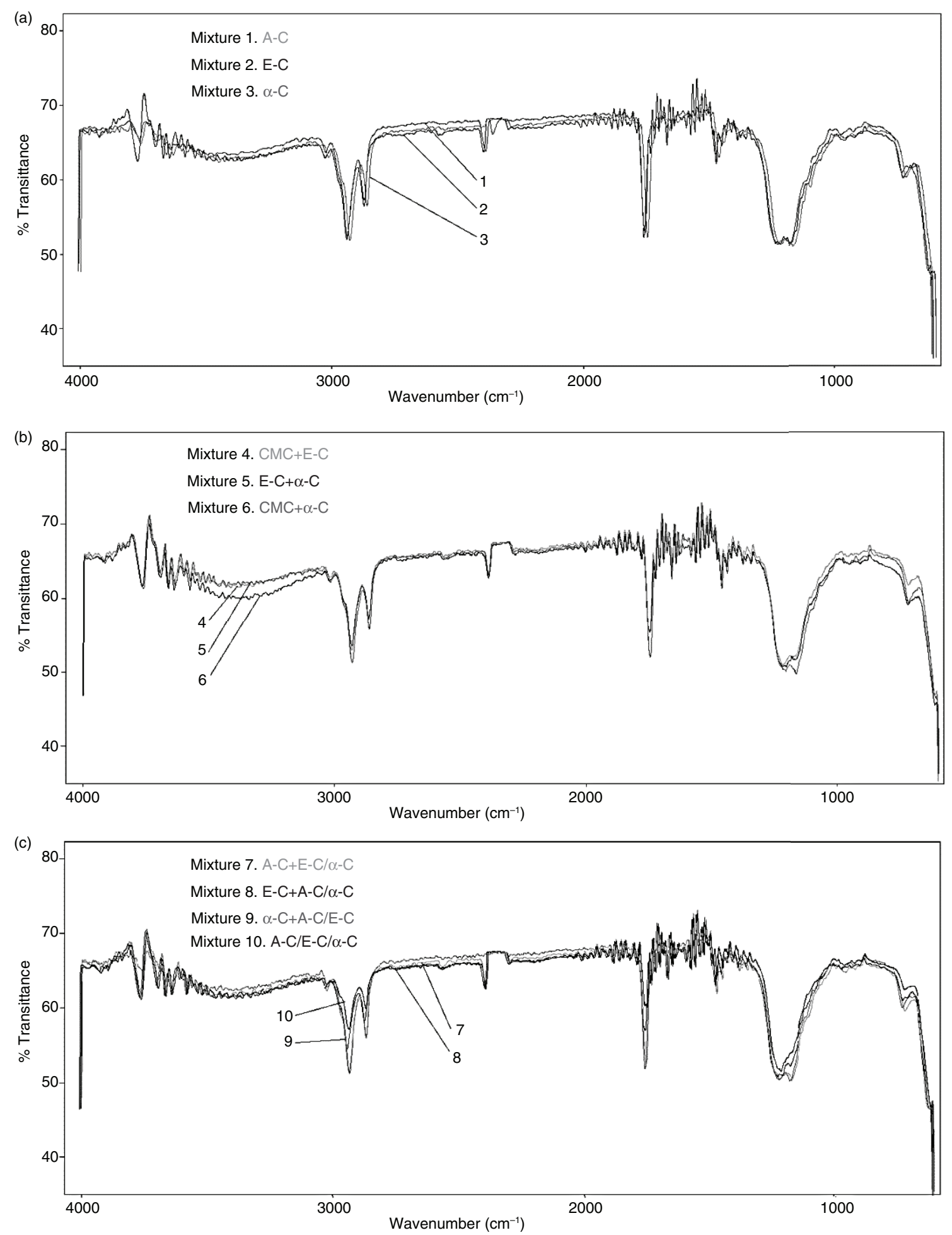

FIGURE 4. FTIR spectra for the different oleogels formulated with Avicel (microcrystalline cellulose/CMC, A-C), ethyl cellulose (E-C) and $\alpha$-cellulose $(\alpha-C)$. 

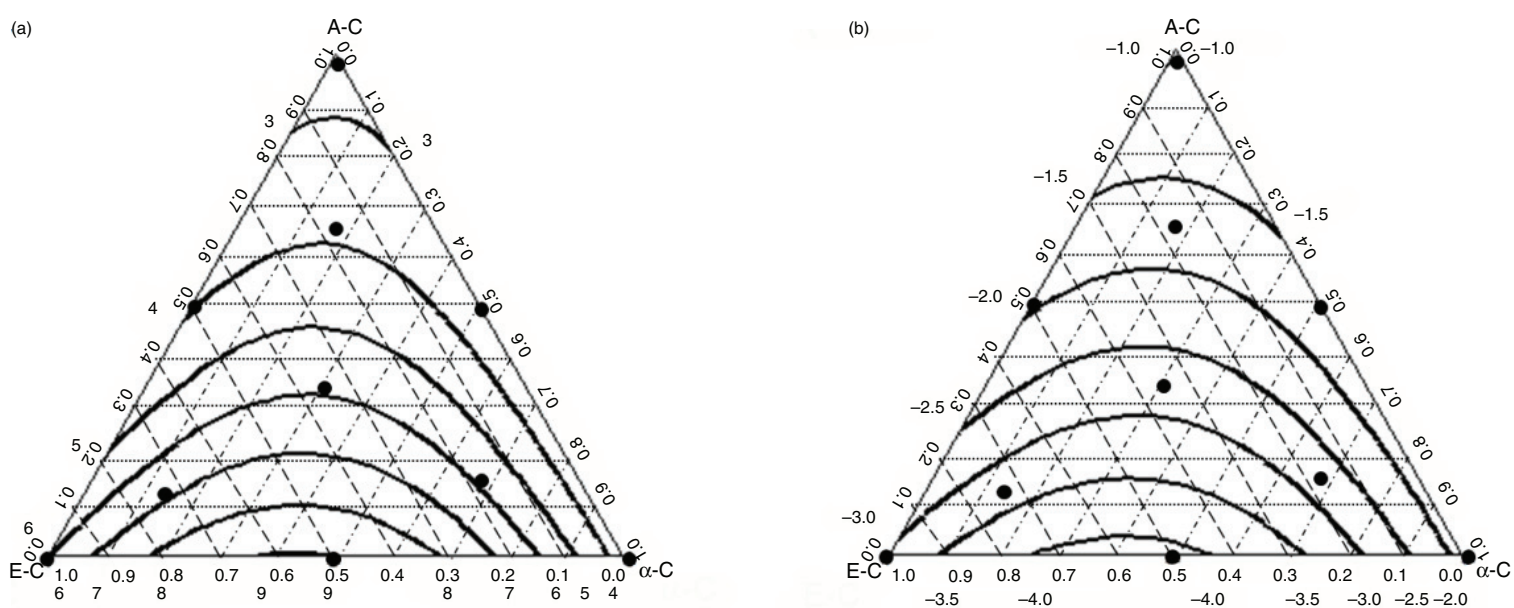

FIGURE 5. Iso-response contour plots of special cubic model for texture for oleogels: (a) maximum force and (b) tackiness (A-C: Avicel microcrystalline cellulose/CMC, E-C: ethyl cellulose, $\alpha$-C: $\alpha$-cellulose).

content due to oil oxidation. Other factors like oxygen incorporation during mixing, could also affect oil stability.

\subsection{Thermal stability by differential scanning calorimetry}

Cellulose derivatives form thermo-reversible gels upon heating. In addition, at high temperatures, the solvent becomes poorer, favoring chain-chain interaction where the type of substitution plays an important role (Guenet, 1992). In the case of oleogels, the non-polar characteristic of the solvent (soybean oil) allows chain-chain interactions. Even after the initial heat applied to induce thermoplastic transition, thermal properties of the studied oleogel mixtures present different thermal stability related to glass transition temperature. The gelation mechanism of several known thermo-reversible systems is based on the formation of secondary structures, but the gelation mechanism of cellulose oleogels does not involve the formation of an ordered secondary structure per se (Davidovich-Pinhas et al., 2015; 2016). Avicel containing mixtures presented a higher transition temperature and enthalpy, due to the presence of $\mathrm{CMC}$ in the mixtures. A more thermally stable oleogel was observed at higher proportions of ethyl cellulose and $\alpha$-cellulose. Thermal susceptibilities (activation energy values) were generally lower for oleogels formulated with ethyl cellulose/ $\alpha$ cellulose blends (Gravelle et al., 2012).

\subsection{Texture}

The texture of oleogels was influenced by the cellulose type. A harder and more adhesive oleogel texture was obtained in ethyl cellulose/ $\alpha$-cellulose mixtures, where the joint contribution of both types of cellulose increased oil viscosity (Sánchez et al., 2011). In same manner, an increase in mechanical strength can be due to hydrogen bond interactions with the ethyl cellulose, contributing to the structural integrity of the gel matrix (Gravelle et al., 2012). Besides hydrogen bonds, hydrophobic interactions between acyl chains of oil and the side chains of ethyl cellulose polymer chains enhance gel stability (Davidovich-Pinhas et al., 2015). The Avicel composition (microcrystalline cellulose and CMC) resulted in a softer and less tacky texture since the particular substituent in CMC, sodium carboxyl, allowed a lower degree of interaction in the formed oleogel structure, besides its hydrophilic character.

\subsection{Fourier transform infrared spectroscopy}

From the $1300-1500 \mathrm{~cm}^{-1}$ region, changes in IR spectra could be due to numerous mixed vibrations rather than characteristic group frequencies, where the bands in this range are mixtures of $\mathrm{OCH}$ deformation vibrations, $\mathrm{CH}_{2}$ bending vibrations, $\mathrm{CCH}$ and $\mathrm{COH}$ bending vibrations (Langkilde and Svantesson, 1995; Proniewicz et al., 2001; Pushpamalar et al., 2006). The band at approximately $3300 \mathrm{~cm}^{-1}$ corresponds to hydrogen bonding between the un-substituted $\mathrm{OH}$ groups of the cellulose backbone (Laredo et al., 2011) (Figure 5).

During oleogel elaboration, cellulose solubilization in oil occurs at temperatures above their glass transition, at the point in which cellulose molecules have energy enough to slide past one another, resulting in a viscous, rubbery, flexible polymer. Polymerpolymer interactions occur within $\mathrm{OH}$ groups of different molecules or of one chain to another, involving only hydrogen bond interactions and no 
direct electrostatic interaction with the oil (Laredo et al., 2011). In this case, the main changes observed in the IR spectra are due to polymer-polymer interaction by hydrogen bounding to form an oleogel structure (above $3000 \mathrm{~cm}^{-1}$ ) and mixed vibrations (C-C stretching, $\mathrm{COH}$ and $\mathrm{CCH}$ deformation/bending vibration, $\mathrm{OCH}$ deformation vibrations, and $\mathrm{CH}_{2}$ bending vibrations) at $1500-1000 \mathrm{~cm}^{-1}$. IR spectra support interaction between the different types of cellulosic derivatives during oil entrapping, resulting in different texture and thermal properties.

\section{CONCLUSIONS}

The type of cellulose derivative affected the oxidative and thermal stability of soybean oil oleogels. Avicel, a commercial mixture of cellulose microcrystalline and $\mathrm{CMC}$, increased the oxidative rancidity and peroxide values of oleogels, as compared to ethyl cellulose and $\alpha$-cellulose. In same manner, higher proportions of Avicel in oleogel increased as well as glass transition temperature of oleogels, due to their thermo-reversible character. High ethyl cellulose and $\alpha$-cellulose proportions in the oleogel mixture resulted in a more stable system with lower oil rancidity and a lower glass transition temperature. Nonetheless, using Avicel resulted in a softer and less tacky texture, an important characteristic to consider for food applications. Other factors to consider in mixed oleogel formulations are the cost of the cellulose derivatives and their GRAS status. Avicel is a widely employed food ingredient, that although seems to promote lipid rancidity and increase glass transition temperatures, as compared to ethyl cellulose and $\alpha$-cellulose, the resulting texture is softer and more adequate to be employed as a replacement for fat in processed foods.

\section{ACKNOWLEDGMENTS}

Part of this research was supported by the project 034.14-PD, "Formulación de oleogeles como substituto de grasa en alimentos" (Oleogel formulation as fat substitute in foods), Tecnológico Nacional de Mexico, México. Mrs. Fragoso thanks Conacyt, Mexico, for her graduate studies grant.

\section{REFERENCES}

AOAC 1999. Official Method 965.33: Peroxide value of oils and fats. Official Method of Analysis of AOAC International (16th Ed.), Washington, DC.

Barros-López TI, Gomez-Coelho R, Yoshida NC, Honda NK. 2008. Radical scavenging activity of orsellinates. Chem. Pharm. B. 56, 1551-1554. http://dx.doi.org/10.1248/cpb.56.1551

Co ED, Marangoni AG. 2012. Organogels: An Alternative edible oil-structuring method. J. Am. Oil. Chem. Soc. 89, 749-780. http://dx.doi.org/10.1007/s11746-012-2049-3
Coffey DG, Bell DA, Henderson A. 2006. Cellulose and cellulose derivatives. In Food Polysaccharides and their Application, 2nd edition. Stephen AM, Phillips GO, Willimas PA (eds.). CRC Press: Boca Raton, 147-179.

Cornell JA. 1980. Experiments with Mixtures: Design Models, and the Analysis of Mixture Data. John Wiley \& Sons: New York.

Dassanayake LSK, Kodali DR, Ueno S. 2011. Formation of oleogels based on edible lipid materials. Curr. Opin. Colloid. Int. Sci. 16, 432-439. http://dx.doi.org/10.1016/j. cocis.2011.05.005

Davidovich-Pinhas M, Barbut S, Marangoni AG. 2016. Development, characterization, and utilization of food-grade polymer oleogels. Ann. Rev. Food Sci. Technol. 7, 4.1-4.27. http://dx.doi.org/10.1146/annurev-food-041715-033225

Davidovich-Pinhas M, Gravelle AJ, Barbut S, Marangoni AG. 2015. Temperature effects on the gelation of ethyl cellulose oleogels. Food Hydrocolloid 46, 76-83. http://dx.doi. org/10.1016/j.foodhyd.2014.12.030

Doan CD, Van de Walle D, Dewettinck K, Patel AR. 2015. Evaluating the oil-gelling properties of natural waxes in rice bran oil: rheological, thermal, and microstructural study. J. Am. Oil Chem. Soc. 92, 801-811. http://dx.doi. org/10.1007/s11746-015-2645-0

Gravelle AJ, Barbut S, Marangoni AG. 2012. Ethyl cellulose oleogels: Manufacturing considerations and effects of oil oxidation. Food Res. Int. 48, 578-583. http://dx.doi. org/10.1016/j.foodres.2012.05.020

Gravelle AJ, Barbut S, Marangoni AG. 2013. Fractionation of ethyl cellulose oleogels during setting. Food Funct. 4, 153-161. http://dx.doi.org/10.1039/c2fo30227f

Gravelle AJ, Barbut S, Quinton M, Marangoni AG. 2014. Towards the development of a predictive model of the formulation-dependent mechanical behaviour of edible oil-based ethylcellulose oleogels. J. Food Eng. 143, 114-122. http://dx.doi.org/10.1016/j.jfoodeng.2014.06.036

Guenet J-M. 1992. Thermoreversible gelation of polymers and biopolymers. Academic Press, London.

Jadhav SR, Hwang H, Huang Q, John G. 2013. Medium-chain sugar amphiphiles: a new family of healthy vegetable oil structuring agents. J. Agric. Food Chem. 61, 12005-12011. http://dx.doi.org/10.1021/jf401987a

Langkilde FW, Svantesson A. 1995. Identification of celluloses with Fourier-Transform (FT) mid-infrared, FT-Raman and near-infrared spectrometry. J. Pharm. Biomed. Analysis, 13, 409-414. http://dx.doi.org/10.1016/0731-7085(95)01298-Y

Laredo T, Barbut S, Marangoni AG. 2011. Molecular interactions of polymer oleogelation. Soft Matter 7, 2734-2743. http://dx.doi.org/10.1039/C0SM00885K

Nikiforidis CV, Scholten E. 2015. Polymer organogelation with chitin and chitin nanocrystals. RSC Adv. 5, 37789-37799. http://dx.doi.org/10.1039/C5RA06451A

Patel AR, Rajarethinem PS, Grędowska A, Turhan O, Lesaffer A, De Vos WH, Van de Walle D, Dewettinck K. 2014. Edible applications of shellac oleogels: spreads, chocolate paste and cakes. Food Funct. 5, 645-652. http://dx.doi. org/10.1039/C4FO00034J

Pernetti M, van Malssen KF, Flöter E, Bot A. 2007. Structuring of edible oils by alternatives to crystalline fat. Curr. Opin. Colloid. Int. Sci. 12, 221-231. http://dx.doi.org/10.1016/j. cocis.2007.07.002

Proniewicz LM, Paluszkiewicz C, Wesełucha-Birczyńka A, Majcherczyk H, Barański A, Konieczna A. 2001. FT-IR and FT-Raman study of hydrothermally degradated cellulose. J. Mol. Struct. 596, 163-169. http://dx.doi. org/10.1016/S0022-2860(01)00706-2

Pushpamalar V, Langford SJ, Ahmad M, Lim YY. 2006. Optimization of reaction conditions for preparing carboxymethyl cellulose from sago waste. Carbohyd. Polym. 64, 312-318. http://dx.doi.org/10.1016/j.carbpol.2005.12.003

Sánchez R, Franco JM, Delgado MA, Valencia C, Gallegos C. 2011. Rheological and mechanical properties of oleogels based on castor oil and cellulosic derivatives potentially 
10 A. Totosaus, R. Gonzaléz-Gonzaléz and M. Fragoso

applicable as bio-lubricating greases: Influence of cellulosic derivatives concentration ratio. J. Ind. Eng. Chem. 17, 705-711. http://dx.doi.org/10.1016/j.jiec.2011.05.019

Stortz TA, Zetzl AK, Barbut S, Cattaruzza A, Marangoni AG. 2012. Edible oleogels in food products to help maximize health benefits and improve nutritional profiles. Lipid Technol. 24, 151-154. http://dx.doi.org/10.1002/ lite.201200205

Yun JM, Surh J. 2012. Fatty acid composition as a predictor for the oxidation stability of Korean vegetable oils with or without induced oxidative stress. Prev. Nutr. Food Sci. 17, 158-165. http://dx.doi.org/10.3746/pnf.2012.17.2.158

Zetzl AK, Marangoni AG, Barbut S. 2012. Mechanical properties of ethylcellulose oleogels and their potential for saturated fat reduction in frankfurters. Food Funct. 3, 327-337. http://dx.doi.org/10.1039/C2FO10202A 